\title{
COVID-19: Nocaute do neoliberalismo? Será possível fortalecer os princípios históricos do SUS e da APS em meio à pandemia?
}

\author{
Luiz Augusto Facchini
}

\section{RESUMO}

A pandemia está revirando concepções e iniciativas de líderes mundiais e nacionais a cada dia e tornou o SUS uma estrela de primeira grandeza no país, reforçando a necessidade de desenvolver um conjunto de intervenções efetivas da APS/ESF. O êxito do SUS, ou seja, da resposta brasileira na redução da velocidade de transmissão do vírus, de sua letalidade e sequelas na população afetada será fundamental para o enfrentamento da epidemia não apenas no Brasil, mas também no mundo, considerando a relevância demográfica, econômica e social do país. Corona vírus tornou-se uma oportunidade histórica de resgatar a centralidade do SUS na política social e da APS no sistema de saúde brasileiro.

Palavras-chave: Pandemia; COVID-19; Atenção Primária à Saúde; Saúde da Família; Saúde Comunitária; Sistemas de Saúde.

Revista da Rede APS 2020

Publicada em: 15/04/2020

DOI:10.14295/aps.v2i1.73

Luiz Augusto Facchini (Universidade Federal de Pelotas, Pelotas, Rio Grande do Sul, Brasil);

Correspondência para: Luiz Augusto Facchini luizfacchini@gmail.com

\section{ABSTRACT}

The pandemic is reversing conceptions and initiatives of world and national leaders every day and has made the SUS a star of first magnitude in the country, reinforcing the need to develop a set of effective interventions of Primary Health Care/Family Health Strategy. The success of SUS, i.e., the Brazilian response in reducing the speed of transmission of the virus, its lethality, and sequelae in the affected population, will be fundamental to confront the epidemic not only in Brazil, but also in the world, considering the demographic, economic, and social relevance of the country. Corona virus has become a historical opportunity to rescue the centrality of SUS in social policy and Primary Health Care in the Brazilian health system.

Keywords: Pandemic, COVID-19, Primary Health Care; Family Health; Community health; Health Systems. 


\section{UMA BREVE HISTÓRIA}

Nos últimos anos, a derrota das políticas de bem-estar e proteção social de governos de centro-esquerda ao redor do mundo, abriu as portas à expansão do neoliberalismo, dos costumes conservadores, do fundamentalismo religioso e dos agrupamentos políticos de extrema direita. Na região das Américas, a hegemonia neoliberal tem sido praticamente absoluta desde 2016, com raras exceções (Uruguai volveu à direita neste ano, México e Argentina giraram à esquerda em 2019). No Brasil, a guinada à direita resultou em rápido aumento de iniquidades sociais, privatizações de bens e recursos públicos, desemprego e precarização do trabalho, com um ataque contínuo às políticas sociais e paralisação dos investimentos públicos. A pobreza e a fome voltam a assombrar o país e a desafiar a resistência das instituições públicas.

Independente das mudanças recentes na política nacional decorrentes do golpe de 2016, as elites liberais do país sempre denunciaram e atacaram o SUS e o Estado de bem-estar social por perdulários e ineficientes. Na curta história da democracia, as forças conservadoras e reacionárias estiveram em constante ataque à saúde pública e a favor da liquidação dos direitos sociais estabelecidos na Constituição Federal de 1988. A hegemonia neoliberal no país distanciou o SUS do sistema proposto pelo Movimento da Reforma Sanitária brasileira e aprovado na Conferência Nacional de Saúde de 1986 e logo, na Constituição Federal de 1988.

Desde 2016 e em particular após a posse de Bolsonaro, o neoliberalismo, por meio da ação explícita de agentes do Estado e de forças econômicas, militares, políticas, jurídicas e midiáticas, promove a destruição dos direitos históricos dos trabalhadores e das políticas dos governos Lula e Dilma nas áreas sociais, como, por exemplo, os ataques às áreas de educação, saúde, ciência e tecnologia. No SUS, os limites de financiamento impostos pela Emenda Constitucional 95 e os esforços para transformar a ESF em pronto-atendimento de horário estendido, centrado essencialmente na livre demanda episódica, resultaram na supressão de elementos críticos do modelo de APS adotado no país desde 1994.

As mudanças nas políticas e ações do SUS afetaram o financiamento da APS, a provisão de pessoal, a educação permanente, o investimento em infraestrutura e o modelo de organização dos serviços da ESF, que ficou mais parecida às UBS do modelo tradicional. As iniciativas produziram o desabastecimento de medicamentos e imunobiológicos, a descontinuidade dos NASF, a redução das equipes de ESF com a saída de profissionais cubanos do Mais Médicos, a diminuição do número obrigatório de ACS por equipe, o aumento das terceirizações e privatizações na APS, fomentando a insegurança funcional e o desânimo da força de trabalho. Protegidas por um discurso de eficiência, melhoria da gestão, racionalidade operacional e otimização de recursos, as mudanças afetaram também as ações de promoção da saúde e prevenção de agravos, ao desprezar objetivamente os conceitos de território e população, categorias centrais da epidemiologia e da saúde pública.

A situação da saúde pública foi ainda agravada por um aumento do empobrecimento e envelhecimento da população, seu maior adoecimento por múltiplas condições crônicas de saúde e uma maior demanda de atendimento no SUS frente a impossibilidade de milhões de pessoas de pagar planos de saúde cada vez mais caros e restritivos. Em síntese, nos últimos cinco anos observou-se uma sistemática fragilização do SUS e da capacidade da rede de serviços públicos de saúde, em especial da APS/ESF de responder adequada e prontamente às necessidades de saúde da população do país.

\section{Presentes de Ano Novo - CRISe e PANDEMIA}

O ano de 2020 começou com crise neoliberal e pandemia de corona vírus. O neoliberalismo brasileiro, seguindo tendência global, já dava mostras de incapacidade em solucionar os 
dilemas econômicos e sociais, frente a cenários devastadores em termos de renda, emprego e capacidade produtiva, desde antes do réveillon. A marcante desindustrialização dos últimos anos expressa o grau de nossa dependência internacional na produção de bens de capital e de consumo previamente dominados pelo país (desde aviões e componentes metalomecânicos, até equipamentos hospitalares e de saúde, passando por EPI, roupas, calçados e mobiliário).

De repente, a pandemia de corona vírus colocou em xeque o neoliberalismo global, tomou conta dos noticiários, das conversas entre familiares, amigos e colegas, do discurso de políticos, autoridades e governantes. Em meio ao isolamento e a quarentena mundo afora, o Banco Mundial e o Fundo Monetário Internacional recomendam para enfrentamento da "coronacrise", que os países apresentem planos fiscais de recuperação econômica, com recursos expressivos para as áreas de saúde e de proteção de populações mais vulneráveis. Reino Unido, Alemanha, Coreia do Sul, Argentina, Chile e Estados Unidos já apresentaram suas propostas.

Na Alemanha, Merkel fala em expansão da dívida pública e do déficit fiscal; nos Estados Unidos, Trump fala em participação do Estado na economia (tema impensável algumas semanas atrás) e libera o caixa para atender demandas de empresas e populações vulneráveis; na Espanha, Pedro Sanchez estatiza hospitais e valoriza as iniciativas públicas. No Brasil, infelizmente, a epidemia exibe mais uma vez ao mundo um governo nacional ridículo, confuso e surpreso com o tamanho da encrenca. Desde o golpe de 2016, o país se tornou uma espécie de chacota internacional, motivo de séria preocupação quanto aos destinos dos brasileiros e o impacto do país na saúde pública global. O mais alto comando do Estado brasileiro foi nocauteado pela pandemia e protagoniza cenas bizarras. Em aparições públicas, declarações e entrevistas, o presidente e seus colaboradores lutam contra as máscaras, incapazes de lhes constranger a liberdade para cuspir ataques aos direitos humanos, à democracia e às políticas sociais e de saúde. A dificuldade em expressar solidariedade às populações mais pobres e vulneráveis e reconhecer o sufocamento dos serviços públicos - principalmente de saúde e educação, como por exemplo, o SUS, a APS, as universidades estatais e as instituições do Estado - é evidente naqueles acostumados a falar em destruir políticas sociais e privatizar bens públicos.

Apesar do continuado deboche e descaso do presidente com a epidemia, em 19 de março de 2020, para desespero de neoliberais e fascistas, o governo Bolsonaro e, particularmente, o Ministério da Saúde se socorreram das políticas públicas efetivadas por Lula e Dilma e que sobreviveram aos trancos e barrancos, por absoluta necessidade de operar as ações do Estado e responder à calamidade nacional e mundial do corona vírus.

\section{A PANDEMIA TORNARÁ O MUNDO DIFERENTE? O QUE QUEREMOS PARA O SUS EA APS?}

A pandemia está revirando concepções e iniciativas de líderes mundiais e nacionais a cada dia. A circulação comunitária do corona vírus e o aumento expressivo de atendimento por problemas respiratórios graves tornou o SUS uma estrela de primeira grandeza no país, reconhecida internacionalmente e, agora, pela mídia nacional, sempre tão crítica de problemas e distraída de alcances. O SUS e a APS/ESF são destaques positivo do país no enfrentamento da pandemia. Quem diria, um vírus obrigou Bolsonaro a retomar o Programa Mais Médicos, a ampliar suas vagas e a recontratar médicos cubanos que permaneceram no Brasil. Mas a súbita utilização e ampliação de vagas e financiamento de um programa tão atacado pelo presidente e auxiliares continua repleta de rancores e desprezo. Bolsonaro continua ingrato aos profissionais cubanos e despreocupado com a saúde dos mais pobres, pois acaba de dispensar do Mais Médicos profissionais 
formados no exterior sem Revalida. O contexto político nacional confuso e conflagrado multiplica ameaças e reduz eventuais benefícios da pandemia ao SUS e ao direito universal, integral e equitativo à saúde.

A pandemia também abriu as portas de programas sociais, fala-se em abono aos trabalhadores informais com registro no cadastro único, extensão do segurodesemprego e o Bolsa Família tem previsão de ingresso maciço de população em situação de miséria. Mas a ação cotidiana do governo federal continua a reforçar o seu caráter neoliberal e excludente. A epidemia chega ao Brasil no momento de menor cobertura nacional do Bolsa Família, desde maio de 2017. No mês de março, já com difusão do corona vírus no país, ocorreu a exclusão de 158.452 beneficiários do programa, $61 \%$ deles residentes na região Nordeste. Além disso, uma das principais promessas de campanha de Bolsonaro, o 13 salário para os beneficiários do Bolsa Família deixa de valer nesta quarta-feira (25), pois a Medida Provisória editada para conceder $\mathrm{o}$ benefício caducou sem ser aprovada.

Ao disponibilizar recursos do tesouro nacional para enfrentar a crise econômica e a pandemia, o governo neoliberal expõe contrariedades e contradições. Os discursos e as análises das lideranças governamentais não raro afrontam as necessidades sociais mais imediatas do país, contrariando a equidade e a razoabilidade na distribuição dos novos aportes financeiros. 0 contexto de crise e tragédia continua a brindar oportunidades de negócios para os grandes atores políticos e econômicos. Os bancos e as grandes empresas se movimentam em busca de muitos bilhões de reais. Prefeitos de capitais, de cidades de regiões metropolitanas e governadores apresentam suas demandas, inclusive falam em centralizar os recursos extras em serviços hospitalares e UTIs, a mídia, em especial as redes de televisão, em sintonia com muitos setores do governo federal desconhecem e/ou negligenciam o papel central da APS na organização de uma coordenação nacional permanente das ações relativas à pandemia.

Os negócios de ocasião se multiplicam com as comprar em grande escala, de modo fragmentado e descoordenado de máscaras, luvas, toucas, aventais, uniformes, álcool em gel, respiradores e ventiladores, leitos hospitalares, equipamentos de apoio, hospitais de campanha, materiais de higiene pessoal e ambiental, medicamentos, dentre outros tantos itens de saúde, juntamente com a grande lista de compras feitas em setores comércio e serviços de alimentação e logística (cestas básicas, quentinhas, transporte, manutenção, ...). A urgência e o descontrole na condução destes processos de compras poderão resultar em desperdício e ineficiência, relacionados tanto a preços exorbitantes, quanto à baixa qualidade dos produtos de alta demanda na economia política do desastre sanitário e social. Em ocasiões anteriores, equipamentos e insumos essenciais ficarão retidos nos portos, aeroportos, almoxarifados e depósitos do país. Logo, é preciso avançar na elaboração de estimativas de necessidade e de custo de produtos, materiais, equipamentos e recursos para suprir o SUS e atender a população, conforme os padrões de evolução da epidemia no Brasil e as predições matemáticas e epidemiológicas de sua dinâmica.

É urgente o apoio à carente infraestrutura especializada de municípios e regiões do Brasil. Muitos dos nossos hospitais, prontos socorros, ambulatórios e serviços especializados espalhados pelo país, especialmente no interior, acumulam deficiências históricas de edificações, equipamentos, pessoal e insumos. Entretanto, a ação centralizada, concentrada em serviços especializados, não será suficiente para enfrentar com êxito o problema do contágio e disseminação da epidemia, em um país de dimensões continentais e desigualdades abissais. Será preciso fortalecer a APS e os pressupostos de ação da ESF e dos ACS. À equipe do território cabe coordenar e monitorar as ações dirigidas à população sob sua 
responsabilidade, em articulação com os serviços especializados e complementares.

Muito bilhões de reais, ou até trilhões de reais, conforme alguns, serão gastos na tentativa de enfrentar a COVID-19 e resgatar a economia do país. O grande desafio será fazer o dinheiro chegar aos mais pobres, miseráveis e vulneráveis, àqueles em piores condições de vida, com risco de adoecimento e morte extremamente maior do que o dos mais ricos. Por analogia, o grande desafio será ampliar o financiamento e a capacidade de resposta da APS no país. Ao descentralizar os investimentos extra decorrentes do enfrentamento à pandemia, se abre a possibilidade de dinamizar a economia desde a base. É possível promover iniciativas que preparem a sociedade para a recessão econômica e os momentos pósepidemia, por meio de incentivos financeiros e técnicos às comunidades, pequenos e médios negócios, do campo e da cidade, universidades, escolas técnicas, centros de pesquisa e desenvolvimento tecnológico na produção de máscaras, EPI, equipamentos de ventilação, camas hospitalares, kits e testes laboratoriais, materiais de comunicação, internet e tecnologia da informação, educação permanente e divulgação de temas de interesse social, redes de apoio social ao isolamento e a quarentena rotineira de idosos, pessoas acamadas e com múltiplas incapacidades.

No balcão das oportunidades e negócios, é razoável e de absoluto interesse público demandar um aumento expressivo do orçamento das ações de APS/ESF no SUS. Os números são desencontrados, mas o ministro da Saúde já falou em um aporte extra de 400 bilhões de reais para o SUS. Se apenas $5 \%$ destes recursos, ou seja, 20 bilhões de reais ao ano for alocado à SAPS, haverá a duplicação dos valores disponibilizados na atualidade pelo governo federal para a APS/ESF. Se o montante extra for de $10 \%$ então o orçamento federal da APS será triplicado. Embora relativamente modestos frente a cifra total mencionada pelo ministro, duplicar, ou mesmo triplicar os recursos da APS alimentará uma rede de serviços com capilaridade social e territorial impressionante. Beneficiará mais de 40 mil equipes de Saúde da Família localizadas tanto em favelas e periferias urbanas densamente povoadas de nossos grandes centros urbanos, quanto nos lugares mais remotos e de difícil acesso do interior do país.

Em função das ações de isolamento e quarentena social de bilhões de pessoas, a pandemia produziu uma aceleração impressionante da revolução tecnológica centrada na informação, na internet, na comunicação online, para adequar os serviços e prover os bens necessários ao bem-estar pessoal a distância e de modo relativamente seguro. Os efeitos dos recursos aplicados na proteção social de populações mais vulneráveis, trabalhadores informais, desempregados e miseráveis serão reforçados, caso se priorize a APS/ESF na alocação dos investimentos e recursos financeiros adicionais, com o propósito de qualificar a atenção às famílias em seus domicílios e a interação continuada a distância com os usuários das UBS.

\section{QUE RESPOSTAS A APS E A ESF PODEM} DAR À PANDEMIA E ÀS NECESSIDADES DE SAÚDE?

A marcante iniquidade social no acesso e na qualidade de serviços essenciais da rede de saúde e o desafio sanitário posto pela pandemia no Brasil requerem uma abordagem familiar e social da determinação social da saúde. As medidas de higiene pessoal e ambiental e de restrição à circulação de pessoas afetam a vida cotidiana com significados diferentes para a saúde e o bem-estar da população de cada área de abrangência da ESF, de cada bairro, favela ou comunidade pobre, de cada município e região do país. Para os grupos sociais mais ricos, com capacidade extra para enfrentar as adversidades econômicas e de saúde decorrentes da epidemia está sendo mais fácil observar as 
recomendações de rigoroso cuidado e assepsia na interação social, reclusão familiar, isolamento entre os membros dos domicílios, interrupção do trabalho e da produção, em uma impressionante quarentena global.

Já as classes populares, os trabalhadores formais e informais, os desempregados, desalentados e miseráveis terão muita dificuldade, ou impossibilidade de guardar tais recomendações e imposições. Em favelas e comunidades pobres, dispersas em municípios pequenos, médios e grandes de todo território brasileiro, falta mais do que produtos e regras de higiene pessoal, falta água, casa, trabalho e dinheiro para enfrentar cada dia. Em consequência, os efeitos da epidemia serão muito mais graves para estes brasileiros, em comparação a seus conterrâneos de classes mais abastadas. Portanto, é preciso ajustar a estratégia nacional de enfrentamento da epidemia à realidade social e aos recursos disponíveis no país. No âmbito público, sabemos bem, nossa fortaleza é a construção do SUS, um sistema universal de saúde, gratuito, integral e de qualidade, com base na APS.

Centrar a estratégia de ação do país na APS/ESF permitirá conhecer a real magnitude da epidemia, contribuir para o alongamento da transmissão do vírus e qualificar a atenção à saúde da população. Para isso, é necessário reforçar e desenvolver um conjunto de intervenções efetivas da APS/ESF. Dentre elas, são listadas algumas para contribuir ao debate em curso na Rede de Pesquisas em APS:

- Garantir o necessário cuidado em condições minimamente seguras a usuários e profissionais de saúde nas UBS. Avaliar a capacidade dos serviços em prover máscaras e salas de isolamento a pessoas com febre, tosse, dor de garganta ou dificuldade respiratória, teste rápido para COVID-19, administração de medicação e suporte respiratório.

- Implementar as vigilâncias sanitária e epidemiológica no território das UBS, com foco nos sintomas da doença (febre, tosse, falta de ar, cansaço, etc) em grupos populacionais, em especial idosos, pessoas com multimorbidade, fatores de risco e agravos sociais em saúde. Contemplar o monitoramento e avaliação dos principais problemas de saúde da população e dos usuários das UBS, como por exemplo, doenças respiratórias, influenza/gripe, pneumonia, HAS/DM, dengue, DST/HIV, multimorbidade e outras enfermidades comuns e agravos de relevância epidemiológica e sanitária.

- Realizar testagem criteriosa do vírus na comunidade, conforme classificação de risco da população e usuário e articular a imediata atenção especializada ao identificar sinais de alerta de emergência para COVID-19, que incluem: grave dificuldade respiratória, dor ou pressão persistente no peito, confusão mental ou incapacidade de despertar, lábios ou rosto azulados.

- Expandir a capacitação e educação permanente a distância de profissionais da APS/ESF e principalmente da população do território. Difundir orientações sobre a pandemia e demais necessidades de saúde da população, com ênfase em autocuidado, cuidado de familiares e pessoas do convívio social que estejam doentes, identificação de sinais de alerta e gravidade com a consequente busca de atendimento, seja ele à distância, em casa, ou presencialmente em algum serviço da rede de saúde.

- Agilizar a implantação universal e a qualificação dos sistemas de informática e informação em saúde, especialmente de notificação epidemiológica e a capacitação das equipes da APS e trabalhadores de saúde na produção de relatórios de monitoramento e avaliação e na utilização dos sistemas para o planejamento das ações. 
- Dinamizar plataformas de monitoramento e avaliação domiciliar de saúde, com notificação de fatores de risco, sinais e sintomas e necessidades de saúde, articuladas aos sistemas de informação em saúde e capaz de direcionar prontamente as ações adequadas a cada situação, em cada família.

- Organizar programa/ações coordenadas em saúde do idoso e monitoramento de multimorbidade e fatores de risco para tomada de decisão e encaminhamentos

- Fortalecer os cuidados domiciliares por parte de ACS, agentes de endemia e profissionais de saúde das equipes básicas como principal estratégia de redução de aglomerações nas UBS e transmissão de corona vírus e mas também para facilitar a implantação de medidas de higiene e proteção pessoal e familiar, juntamente com os efeitos do isolamento e da quarentena.

- Promover visitação virtual a todos os domicílios na micro área de cada ACS, registrar eventuais situações de saúde passíveis de notificação e de encaminhamento.

- Articular a internação domiciliar de pessoas do território da ESF com o Programa Melhor em Casa e o SAMU, em caso de remoção para hospitais e serviços especializados.

- Receber o apoio sistemático de especialistas dos NASF, Tele Saúde e da regulação dos serviços especializados, ambulatoriais e hospitalares.

- Evitar a concentração de ações em prontosocorro, UPA, ambulatórios hospitalares, tendas e barracas especializadas

- Definir as pesquisas e avaliações em APS e saúde coletiva necessárias ao enfrentamento da pandemia e fortalecimento da estratégia nacional.

\section{TentATIVA de SÍNTESE}

O fortalecimento da ESF, da APS e do SUS no enfrentamento da pandemia facilita a atenção e a orientação de toda população do país. Também qualifica o cuidado de pessoas com corona vírus e outros agravos à saúde, como por exemplo, vírus da influenza, infecções respiratórias bacterianas, que aumentam a utilização de recursos mais especializados, leitos de UTI e ventilação mecânica. A coordenação proativa das ações de APS/ESF no território tem elevado potencial de reduzir a disseminação do vírus na população e a gravidade clínica dos casos.

Essa coordenação será mais efetiva e eficiente se valorizar os pilares básicos do modelo de ESF, desenvolvido com bons resultados por mais de duas décadas no país, conforme atesta a produção científica da academia e dos serviços de saúde. A ESF tem sido capaz de modificar positivamente o padrão de sobrevivência da população mais pobre, inclusive dos idosos, nossa maior preocupação no momento. Um maior acesso e qualidade da APS, a integralidade e a equidade de suas ações no território serão essenciais na resposta individual e populacional à epidemia.

A Rede de Pesquisa em APS tem organizado propostas objetivas para o setor, como por exemplo, a "Contribuição para uma agenda política estratégica para a Atenção Primária à Saúde no SUS". Suas atividades em cooperação com a Organização Pan-Americana da Saúde, em especial com o Laboratório de Inovação em APS Forte, também servem de referência para as ações de desenvolvimento da APS no SUS.

O corona vírus é uma oportunidade histórica de resgatar a centralidade do SUS na política social e da APS no sistema de saúde brasileiro. O forte apoio do Estado e da sociedade brasileira à organização pública da saúde possibilitará ao SUS avançar significativamente no alcance de seus princípios de universalidade, integralidade e equidade. Para viabilizar uma rede de serviços completos e complexos, distribuída em todo o 
país, o SUS poderá estatizar serviços privados e celebrar contratos de exclusividade com instituições privadas, filantrópicas e públicas, cujos serviços são essenciais à rede de atenção do SUS, como, por exemplo, hospitais, laboratórios, clínicas especializadas em saúde, provisão de insumos e materiais e centros de pesquisa, inovação e desenvolvimento científico e tecnológico.

O êxito do SUS, ou seja, da resposta brasileira na redução da velocidade de transmissão do vírus, de sua letalidade e sequelas na população afetada será fundamental para o enfrentamento da epidemia não apenas no Brasil, mas também no mundo, considerando a relevância demográfica, econômica e social do país. Será igualmente uma oportunidade ímpar do país superar sua dívida histórica com a APS e o SUS, em plena crise do capitalismo neoliberal. A
ABRASCO juntamente com entidades da reforma sanitária, instituições apoiadoras da Rede de Pesquisa em APS, associações de profissionais de saúde, centros de formação, pesquisa e inovação em saúde, movimentos sociais e populares, rede sociais e mídias tradicionais e alternativas poderá contribuir para a alocação criteriosa dos recursos extra orçamentários em saúde em favor do SUS e da ESF. A Rede de Pesquisa em APS está mobilizada para apoiar a formulação de propostas embasadas cientificamente para o desenvolvimento da APS. Também apoia o diálogo e a articulação com secretários municipais e estaduais de saúde, CNS e demais conselhos de saúde, prefeitos, governadores, parlamentares locais, estaduais e nacionais, técnicos do Ministério da Saúde para tornar efetivo o fortalecimento da APS no SUS. 